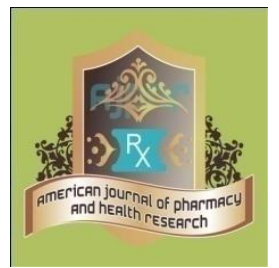

Review Article
AMERICAN JOURNAL OF PHARMACY AND HEALTH RESEARCH
www.ajphr.com

2018, Volume 6, Issue 03

ISSN: 2321-3647(online)

\title{
Liquisolid Technique : A Novel Approach For Enhancement of Solubility and Bioavailability
}

\author{
Jain Urvashi *, Sohaney Nikita, Malviya Sapna \\ Modern Institute of Pharmaceutical Sciences, Indore (M.P.)-452001
}

\begin{abstract}
Liquisolid strategy is otherwise called powder solution technology. It is the system which manages the solubility upgrade of inadequately solvent medications. As nowadays there are numerous medications in the market with poor solvency which prompts poor disintegration and bioavailability, so dissolvability is getting to be rate constraining component in the advancement of new medications. To defeat this issue there are numerous systems yet liquisolid strategy is most encouraging procedure which is talked about in this article. Liquisolid is for the most part made out of medication, non volatile solvent, carrier material, coating material, and disintegrant. In liquisolid strategy carrier and coating material which ought to be in the proportion of 20:1 is blended into the non volatile solvent and after that disintegrant is included and last material is packed into tablets. Henceforth, the liquisolid innovation permits the change of fluid frameworks into strong medication conveyance frameworks. Both quick and managed arrival of medication can likewise be accomplished with the assistance of liquisolid procedure. For sustained release of medication hydrophilic polymer like Hydroxy Propyl Methyl Cellulose can be the best choice. The motivation behind this article is to depict about the liquisolid strategy like basics, classification, preformulation examines, characterization, pre compression contemplates, detailing of tablet, post compression thinks about, points of interest, drawbacks, applications.
\end{abstract}

Keywords: Liquisolid, bioavailability, dissolution, sustained release. 


\section{INTRODUCTION}

With the appearance of combinational science and inventive high-throughput screening, information concerning physicochemical properties (i.e., crystal structures and salt improvement) and what's more organic elements, (for instance, preparing impetuses and transporters) of drug candidates has been broadly aggregated (Lipinski C.A. et al .,2001) As an outcome, countless pharmaceutical fixings have been delivered. Be that as it may, a large portion of these medications are exceptionally lipophilic and ineffectively water-soluble ( Stegemann S.et al., 2007) .It is accounted for that around $40 \%$ of the recently created drugs and about $60 \%$ of the synthesized compound substances experience the ill effects of solubility issues ( Giliyar C. et al .2006) .Consequently, to upgrade the solubility and dissolution of these inadequately watersolvent medications and enhance their bioavailability involve worry for some pharmaceutical scientists. The bioavailability of these Biopharmaceutical Classification System Class II (BCS II) drugs is frequently constrained by their solvency and dissolution rate in the gastrointestinal tract (Amidon G.L. et al., 1999) (Yadav A.V. et al .,2010).

Numerous reasonable detailing approaches have been produced to build the solubility of inadequately water-soluble drugs. Micronization method is the most ordinarily utilized way to deal with enhance drug solvency because of an expansion in surface range, yet the agglomeration inclination of micronized hydrophobic medications makes it less successful to evade the dissolvability issue, particularly when the medication is planned into tablets or epitomes (Aguiar A.J. et al.,1979 ) (Aguiar A.J. et al.,1979 ) Strong scattering has picked up a dynamic research enthusiasm for enhancing drug disintegration in the previous couple of decades, however its business application is extremely constrained and just a couple of items, for example, Kaletra® and Gris-PEG® have become commercially available. The reason principally lies on its poor strength amid capacity and absence of comprehension of its solid state structure (Craig D.Q.M. .,2002). Formulating soft gelatin capsules is another generally utilized approach, though it is expensive and requires advanced innovations (Ebert W.R. .,1977).

Different methodologies, for example, inclusion complexation (Hiremath S.N.et al.,2008) microencapsulation (Li D.X et al.,2008) and readiness of nano suspensions (Kocbek P.et al.,2006) ,self-nanoemulsions (Mahmoud E.B.et al.,2014 ) and strong lipid nanoparticles (Müller R.H. et al., 2006) have additionally been examined for dissolution improvement of inadequately water-soluble drugs. Be that as it may, these methodologies include high generation cost and involve propelled planning technique and additionally refined hardware. Liquisolid 
procedure, a recently created and propelled strategy for dissolution upgrade, can beat numerous previously mentioned hindrances (Javadzadeh Y.et al., 2009) (Elkordy A.A.et al., 2013) (Suliman A.S. et al.,2014). This strategy was first presented by Spireas et al. furthermore, connected to fuse water insoluble medications into quick discharge strong dose forms. The plan guideline of liquisolid framework is to contain fluid pharmaceuticals (i.e., fluid medications, drug solutions or suspensions) in powdered shape and delivery drug in a similar way to soft gelatine cases containing fluids. Liquisolid strategy alludes to the change of fluid drugs into clearly dry, non-adherent, free streaming and compressible powder blends by mixing the fluid meds with appropriate excipients, which are by and large named as carriers and coating materials (Spireas S. et al.,1999) (Spireas S. .,2002). The fluid pharmaceutical is first ingested into the inside system of the transporter. Once the inside of the bearer is immersed with fluid solution, a fluid layer is shaped on the surface of transporter particles, which is right away adsorbed by the fine covering materials. Therefore, an obviously dry and free streaming and compressible powder blend is framed. The instrument of liquisolid framework arrangement is shown in Fig. 1. For the most part, orally sheltered, and best water miscible natural solvents with high boiling point, for example, propylene glycol and polyethylene glycol (PEG) 400, are utilized as the fluid vehicles. Carriers allude to permeable materials with large surface area and high fluid assimilation ability to ingest fluid drug (Spireas S. ., 2002). Various evaluations of cellulose, starch and lactose can be received as carriers. Be that as it may, just Excipients with fine molecule estimate and very adsorptive property, for example, silica powder, can be utilized as covering materials (Spireas S. et al.,1998).Despite the fact that the drug within liquisolid system is in a solid state, it exists exactly in a completely or partly molecularly dispersed state (Fahmy R.H. et al.,2008) (Komala D.R. et al.,2015). In this manner, a liquisolid framework may show upgraded dissolution rate because of the expanded dissolution range, upgraded fluid solvency, or enhanced wetting properties (Sanka K. et al.,2014)

Aside from dissolution upgrade, liquisolid strategy has as of late been explored as a tool to retard drug discharge (Javadzadeh Y.et al.,2008) ( Nokhodchi A.et al.,2010) (Pavani E. et al.,2013 ) to limit the impact of to $\mathrm{pH}$ variation on dissolution profile (El-Hammadi M.et al.,2012 ) ( Badawy M.A. et al.,2016 ), and to enhance drug photostability ( Khames A. .2013) .At last, it merits saying that liquisolid frameworks are not related with strength issues [(Javadzadeh Y. et al.,2008) (Javadzadeh Y. et al.,2007) (Chella N. et al.,2007 ). This study introduces a research of the liquisolid system and the progress in its applications in pharmaceutics. 


\section{Definitions}

\section{Liquisolid systems}

Liquisolid systems are powdered types of fluid medication formulated by converting liquid lipophilic drugs, or drug suspensions or arrangements of water insoluble drug medications in reasonable non-unstable dissolvable frameworks, into dry, non-adherent, free-streaming and promptly compressible powder admixtures by mixing with selected carrier and coating materials.

\section{Liquid medication}

Liquid medication incorporates fluid lipophilic drugs and drug suspensions ,solutions of solid water insoluble drugs in reasonable non- volatile solvent systems (Rajesh K. et al.,2011 )

\section{Non-volatile solvent}

Non- volatile solvent might be hydrophilic or lipophillic in nature relying on the kind of formulation like immediate release or sustained release. Non-volatile solvent ought to be inert, high boiling point, water miscible (Patil U. et al., 2012 ).

\section{Carrier material}

Carrier material alludes to an ideally porous material having adequate retention properties, for example, microcrystalline and amorphous cellulose, which contributes in fluid absorption (Patil

\section{U.et al.,2012 ).}

\section{Coating material:}

Coating material alludes to a material having fine and exceptionally adsorptive particles, for example, different sorts of silica, which contributes in covering the wet carrier particles and showing a dry looking powder by adsorbing any abundance fluid. Besides substitution of ordinarily utilized carrier and coating materials like Avicel and Aerosil separately with Fujicalin and Neusilin prompted impressively higher fluid adsorption limit on account of extensive particular surface area and great flow property (Patil U. et al.,2012 ) (Sambasiva Rao A. et al.,2011)

\section{Disintegrant}

$5 \%$ of disintegrant is utilized as a part of formulation; for the most part Sodium Starch glycolate is utilized as disintegrant (Chandel P. et.al 2013).

\section{Classification of liquisolid systems}

Based on the type of liquid medication contained in that, liquisolid systems are characterized into three sub-groups.

1) Powdered drug solutions

2) Powdered drug suspensions 
3) Powdered liquid drugs

Powdered drug solutions and suspensions might be prepared from the change of drug solution or drug suspensions into liquisolid frameworks and powdered fluid drugs are created from the formulation of fluid drugs into liquisolid frameworks.

Simultaneously, in view of the plan procedure utilized, liquisolid frameworks might be grouped into two classifications in particular,

1) Liquisolid compacts

2) Liquisolid Microsystems

The expression "liquisolid compacts" alludes to immediate or sustained release tablets or capsules arranged and joined with the incorporation of proper adjuvants required for tabletting or encapsulation, for example, lubricants, and for fast or sustained release activity, for example, disintegrants or binders.

The expression "liquisolid Microsystems" alludes to capsules arranged by joining the drug with carrier and coating materials with consideration of an additive e.g., PVP in the fluid drug wherein the subsequent unit size might be as much as five times that of liquisolid compacts (Sambasiva Rao A. et al.,2011).

Main components of liquisolid technique are represented in table no 1.

Table 1: Components of Liquisolid Technique

\begin{tabular}{|c|c|c|}
\hline S.No & Composition & Examples \\
\hline 1. & Drug Candidates & $\begin{array}{l}\text { Hydrochlorothiazide, Digitoxin, Prednisolone } \\
\text { Hydrocortisone, Spironolactone, Digoxin etc. }\end{array}$ \\
\hline 2. & $\begin{array}{l}\text { Non volatile } \\
\text { Liquids }\end{array}$ & $\begin{array}{l}\text { Poly Ethylene Glycol 200, Poly Ethylene Glycol 300, } \\
\text { Poly Ethylene Glycol 400, Glycerine, Propylene Glycol, } \\
\text { fixed oils etc }\end{array}$ \\
\hline 3. & Carrier Materials & $\begin{array}{l}\text { Microcrystalline Cellulose }{ }_{\mathrm{P}} \mathrm{H} \text { 101, Microcrystalline } \\
\text { Cellulose }{ }_{\mathrm{P}} \mathrm{H} \text { 200, Lactose, Methyl Cellulose, Ethyl } \\
\text { Cellulose, Starch1500, Ethocel, Eudragit RL, Eudragit RS } \\
\text { 12, Hydroxy Propyl Methyl Cellulose K4M, Hydroxy } \\
\text { Propyl Methyl Cellulose K100M, Xanthum Gum, } \\
\text { Guargum. }\end{array}$ \\
\hline 4. & Coating Materials & $\begin{array}{l}\text { Aerosil 200, Silica (Cab-O-Sil M5), Syloid 244FP, and } \\
\text { Colloidal Silicon Dioxide. }\end{array}$ \\
\hline 5. & Disintegrants & $\begin{array}{l}\text { Sodium Starch Glycolate (Explotab, Primogel), } \\
\text { Croscarmellose Sodium, Cross Polyvinyl Pyrrolidine, } \\
\text { Pregelatized Starch. }\end{array}$ \\
\hline 6. & Glidant & Talc \\
\hline 7. & Lubricant & Magnesium Stearate \\
\hline 8. & $\begin{array}{l}\text { Release retardant } \\
\text { material }\end{array}$ & $\begin{array}{l}\text { Eudragit RS, RL, Hydroxy Propyl Methyl Cellulose } \\
\text { K100M, K15M, K4M. }\end{array}$ \\
\hline
\end{tabular}




\section{Theory of liquisolid system}

A powder can just hold limited measure of fluid medication while keeping up adequate flowability and compressibility. Accordingly, to accomplish a liquisolid framework with adequate flowable and compressible properties, a mathematical model Liquids (Liquid drug, drug solution, drug suspension) Carrier particles. Incorporation of fluids Carrier soaked with fluids A fluid layer shaped on molecule surface Addition of coating particles Conversion from a wet to a dry surface introduced and approved by Spireas is prescribed to ascertain the calculate amounts of carrier and coating material (Spireas S. et al.,1999) (Spireas S. .,2002) ( Spireas S.S. et al.,1992).

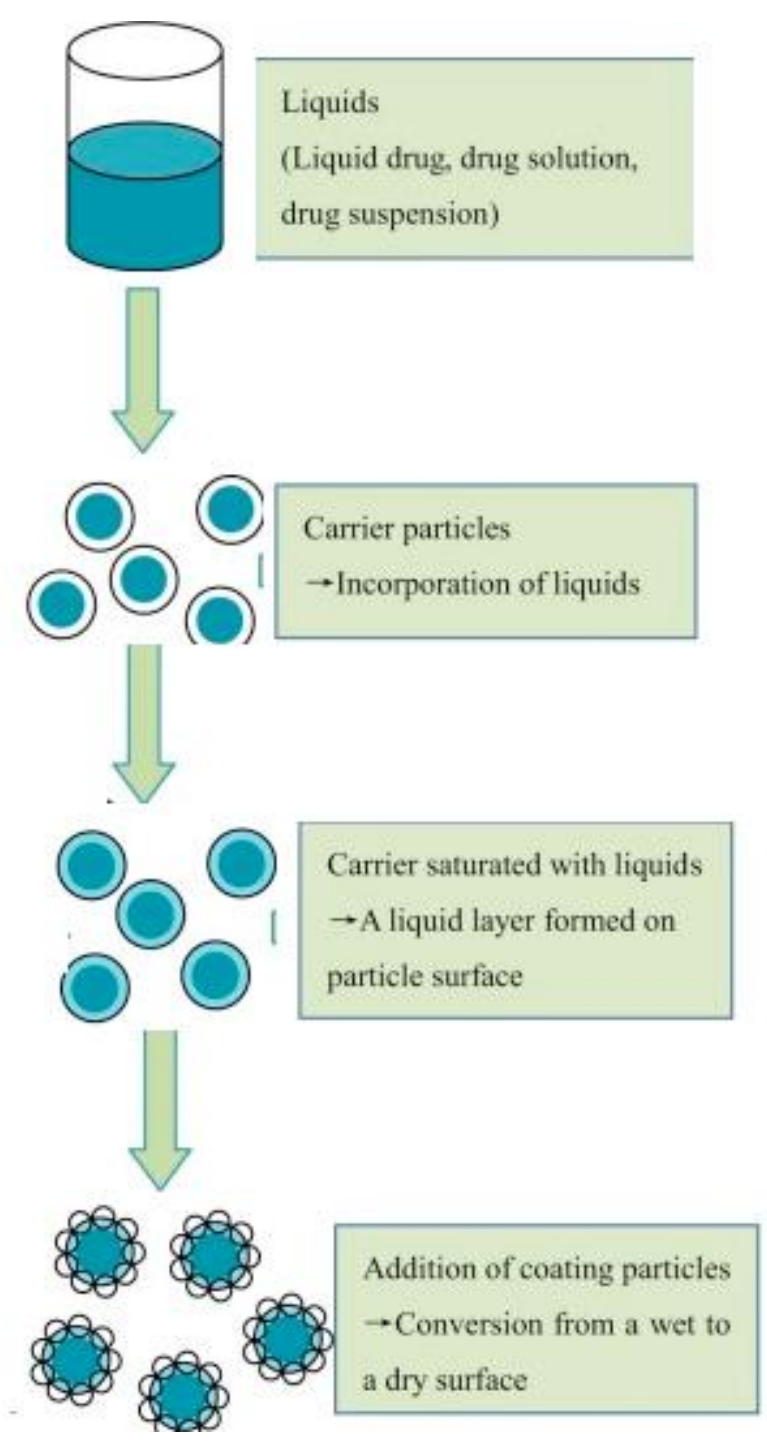

Figure 1: Mechanism of liquisolid system formation ( Spireas S.S. et al.,1992).

The model depends on two basic properties of a powder, i.e., flowable liquid retention potential ( $\Phi$ value) and compressible liquid retention potential ( $\Psi$ value). The $\Phi$ and $\Psi$ estimations of a powder Excipient represents the most extreme amount of liquid vehicle that can be held in the 
powder mass without compromising flowability and compressibility (Spireas S. .2002).The $\Phi$ value is ideally dictated by measuring the angle of slide of the arranged liquid- powder admixture. And the $\Psi$ value can be measured by an investigation called pactisity, which is characterized as the greatest crushing strength of a tablet with a tablet weight of one gram when compressed at adequate compression force (Spireas S. .2002) ( Spireas S. et al.,1998). The Excipients proportion $(\mathrm{R})$, which is otherwise called the carrier/coating proportion, is characterized as takes after:

$$
\mathbf{R}=Q \boldsymbol{q}
$$

In this manner, $\mathrm{R}$ is the proportion between the weights of carrier ( Q) and coating material ( $\mathrm{q}$ ). An increase in the $\mathrm{R}$ value will results in higher amounts of the carrier and lower measures of the coating material. As the $\mathrm{R}$ value is related with the flowability and compressibility properties, disintegration, and dissolution rate of the liquisolid framework, an ideal estimation of $\mathrm{R}$ is prescribed to be 20 ( Spireas S. et al.,1998) (Rajesh K. et al.,2011). Another important parameter of the liquisolid framework is named as liquid loading factor ( Lf ), which is characterized as the weight proportion of the liquid medication (W) and the carrier material ( Q) in the liquisolid framework.

$$
L f=W Q
$$

The liquid loading factor for the production of a liquisolid system with acceptable flowability can be determined by:

$$
\Phi L f=\Phi+\phi \mathbf{R}
$$

Where $\Phi$ and $\phi$ values correspond to the flowable liquid retention potential of the carrier and coating material, respectively. Correspondingly, the liquid loading factor to ensure acceptable compressibility of a liquisolid system can be determined by:

$$
\Psi L f=\Psi+\Psi \mathbf{R}
$$

Where $\Psi$ and $\psi$ esteems relate to the compressible liquid retention potential of the carrier and coating material, individually. Thusly, the ideal liquid loading factor $\left(\mathrm{L}_{0}\right)$ that delivers a liquisolid framework with satisfactory flowability and compressibility is equivalent to either $\Phi \mathrm{Lf}$ or $\Psi \mathrm{Lf}$, whichever has the lower value As $\Phi, \Psi, \phi$, and $\psi$ values are constants for each powderfluid combination, for a given excipients proportion $(\mathrm{R})$, the ideal liquid loading factor $\left(\mathrm{L}_{0}\right)$ can be ascertained by Equations (3) or (4).Then, as per different drug concentrations, distinctive weights of liquid drug (W) will be utilized. In this way, based on calculated $\mathrm{L}_{0}$ and $\mathrm{W}$, the appropriate quantity of carrier ( $\mathrm{Q}_{\mathrm{o}}$ ) and coating material ( $\mathrm{q}_{\mathrm{o}}$ ) can be computed by Equations (1) and (2), separately. 


\section{Advantages and disadvantages of liquisolid technique}

Advantages (Elkordy A.A. et al.,2013) ( Khames A. .,2013) (Patil U. et al.,2012 ) (Sambasiva

Rao A. et al.,2011)

Numerous advantages of liquisolid technique have been reported.

1. Huge number of slightly water-soluble, very slightly water-soluble and practically waterinsoluble drugs can be formulated into liquisolid systems with enhanced dissolution and bioavailability.

2. Sustained release formulations with zero order release pattern can be achieved provided that hydrophobic carriers, such as Eudragit ${ }^{\circ}$ RL and RS, or retarding agents such as hydroxypropyl methylcellulose (HPMC) are used in the liquisolid systems.

3. This strategy can possibly deliver liquisolid tablets or capsules with $\mathrm{pH}$-independent drug discharge profiles.

4. It is a promising contrasting option to traditional coating approach for the change of drug photostability in solid dosage forms.

5. The connected Excipients are effortlessly accessible and cost effective. In addition, the preparation procedure is basic, which is similar to traditional solid dosage forms (i.e. tablets and capsules). In addition, the great flowability and compressibility of liquisolid powder make the strategy attainable for large scale generation.

\section{Disadvantages (Chandel P. Et.al 2013) (Tayel S.A. et al.,2008 )}

There are also disadvantages associated with liquisolid technique.

1. The strategy is effectively connected for low dose water-insoluble drugs, though the consolidation of high dosage water-insoluble drugs into liquisolid frameworks is its primary restriction. As these medications require huge amount of liquid vehicle, hence, keeping in mind the end goal to acquire liquisolid powder with good flow and compressible properties, a lot of carrier and coating material are required. This may build tablet weight over the point of confinement, which is troublesome for patients to swallow. A few systems have been accounted for to address the above deterrent. For instance, including a few added substances (i.e., PVP and PEG 35000) into the fluid solutions to build the thickness can diminish the amounts of carrier and coating material. Also, utilization of current carrier and coating materials, (for example, Fujicalin ${ }^{\circledR}$ and Neusilin $\left.®\right)$ with expansive specific surface area (SSA) and high absorption limit is another effective approach to load high dose water-insoluble medications. 
2. A high solvency of medication in liquid vehicle is required to prepare liquisolid system.

\section{Limitations (Lakshmi M.S. et al.,2012 )}

1. High solubility of drug in the non-volatile liquid drugs for the improvement of dissolution rate and bioavailability.

2. It requires Excipients of high adsorption properties and high specific surface area.

3. It is not applicable to high dose insoluble drugs (>100 mg).

4. During compression sometimes liquid drug may be squeezed out of the tablet result in improper hardness.

\section{Mechanism of enhanced drug release from liquisolid systems (Spireas S. .,2002) (Fahmy R.H. et al.,2008 )}

The three principle components included that are an increased surface area of medication accessible for release, an increased aqueous solubility of the medication and an increased wettability of the medication particles. Here, DSC and XRPD Measurements are utilized to decide any adjustment in crystallinity of the medication or arrangement of the complex between the medication and Excipients.

\section{Increased drug surface area}

In liquisolid framework, if the medication is totally soluble in the fluid vehicle, it is situated in the powder substrate still in a solubilized, molecularly scattered state. Because of, the surface range of medication accessible for discharge is significantly more noteworthy than that of medication particles inside straightforwardly compressed tablets.

In this way, with expanding drug content, as far as possible the solubility limit also increases and thus, increasing the fraction of undissolved medication in the fluid vehicle and along these lines, the release rate diminishes. The release rate is specifically corresponding to the fraction of the molecularly scattered medication (FM) in the liquid formulation.. FM is characterized by Spireas as the proportion between the drug concentration $(\mathrm{Sd})$ in the fluid vehicle and the real drug concentration $(\mathrm{Cd})$ in this vehicle conveyed by every system.

Therefore:

\section{$\mathbf{F M}=\mathrm{Sd} / \mathrm{Cd}$}

Where, $\mathrm{FM}=1$ if $\mathrm{Sd} \geq \mathrm{Cd}$.

\section{Increased aqueous solubility of the drug}

In addition, of the first mechanism of drug release enhancement it is anticipated that Cs, the solubility of the drug, might be increased with liquisolid system. In fact, the relatively small 
amount of the liquid vehicle in a liquisolid compact is not sufficient to increase the overall solubility of the drug in the aqueous dissolution medium. It is possible that a small amount of liquid vehicle diffuses from the total amount along with drug and if the liquid vehicle acts as a co-solvent, this less amount of vehicle is adequate to increase the aqueous solubility of drug. Also, of the main component of drug release improvement it is expected that Cs, the solvency of the drug, may be increased with liquisolid system. In fact, the moderately little amount of the fluid vehicle in a liquisolid compact isn't adequate to increase the general solubility of the drug in the watery dissolution medium. It is conceivable that a little amount of fluid vehicle diffuses from the aggregate amount along with drug and if the fluid vehicle act as a co-solvent, this less quantity of vehicle is satisfactory to increase the aqueous solubility of drug.

\section{Improved wetting properties}

If the fluid vehicle goes about as a surfactant, it can enhance the wettability of the liquisolid system by decreasing the surface tension. Wettability of liquisolid framework has been shown by estimation of contact of angles 8 and water rising circumstances.

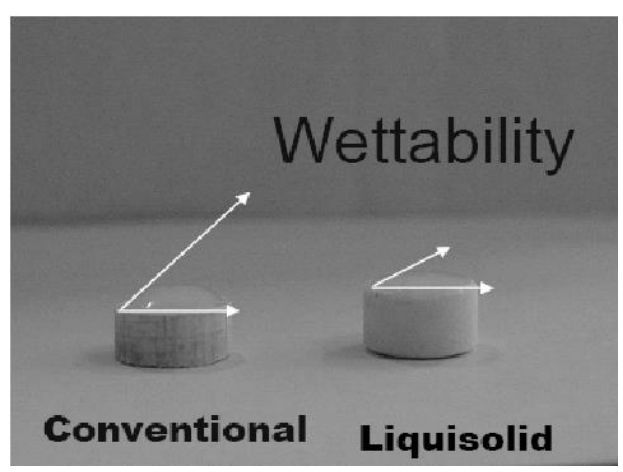

Figure 2: Comparison of wettability between conventional tablet and liquisolid compacts Applications of liquisolid technique in pharmaceutics (Lakshmi M.S. et al.,2012 )

1. Improvement of solubility and dissolution rate in drugs like Indomethacin, Famotidine, Furosemide, Naproxen, Prednisolone, Bromhexine Hydrochloride, Carbamazapine, Rofecoxib, Piroxicam and so forth.

2. Improvement of bioavailability of drugs like Atorvastatin Calcium, Hydrochlorthiazide, Repaglinide, Famotidine and so forth.

3. Preparation of sustained release tablets by the utilization of hydrophobic carriers like Propanolol Hydrochloride, Tramadol Hydrochloride, and Theophylline and so forth.

4. It is also used in probiotics.

5. Controlled release formulations are also formulated by the utilization of different types of carriers that shows the zero order release similar to osmotic pumps. 
6. This method is widely used for liquid lipophilic drugs / oily drugs. (Chandel P.et.al.,2013)

\section{PREFORMULATION STUDIES OF DRUG}

1. Determination of solubility of the drug in different non volatile solvents.

2. Determination of angle of slide.

3. Determination of flowable liquid retention potential.

4. Calculation of liquid load factor $\left(\mathrm{L}_{\mathrm{f}}\right)$

5. Flow properties of the liquisolid system

6. Calibration curve

7. Melting point

\section{Determination of solubility of the drug in different non volatile solvents}

This examination was completed by planning saturated solution of drug in various non-volatile solvent .The saturated solution was set up by including excess amount of medication in different non volatile solvent. This arrangement was then shaked by utilizing shaker for a particular timeframe. Subsequent to shaking this arrangement is then separated and is analyzed by utilizing spectrophotometer. The solution which was having best solubility in drug was selected.

\section{Determination of angle of slide}

This test was done for examining flow behaviour of the powders. In this stream properties were measured by utilizing a very much cleaned metal slide. A required measure of powder was weighed and was taken on the metal slide. This metal slide was raised by its one end till powder particles on the slide begins to stream. At that point the angle between the horizontal surface and the slide was measured which was only the angle of slide. Angle of $33^{\circ}$ is considered as ideal point of slide (Tayel SA et al.,2008)

\section{Determination of flowable liquid retention potential ( $\phi$ value)}

The term fluid retention potential is only it is the capacity of the powder to hold particular measure of fluid in to it and furthermore keep up great stream conduct.

The $\Phi$ value was characterized as maximum amount of fluid held per unit weight of the powder material in order to indicate stream capacity in a worthy range.

$\Phi$ value can be ascertained by utilizing following formula.

\section{$\Phi$ value $=$ weight of liquid /weight of solid.}

\section{Calculation of liquid load factor}

For this different concentrations of non volatile solvent were used and particular measure of drug was dispersed in it. This blend was included to the coating material-carrier material admixture 
and it was mixed. After this drug loading factors were figured for deciding measure of every carrier and coating material in each of the formulation

Formula: Loading factor=Wt. of liquid drug/wt. of carrier material. (Spireas S et al.,1992)

\section{Flow properties of the liquisolid system}

Angle of repose: Angle of repose was calculated by fixed funnel method. The frictional forces in loose powder or granules was measurement by the angle of repose. This is the maximum angle possible between the surface of a pile of powder or granules and the horizontal plane. Thus, $r$ being the radius of the base of the conical pile.

$$
\operatorname{Tan} \theta=\mathbf{h} / \mathbf{r}
$$

Table 8: Angle of Repose (Vraníková B et al.,2013 )

\begin{tabular}{lll}
\hline S. No. & Flow property & Angle of repose (degrees) \\
\hline 1. & Excellent & $25-30$ \\
2. & Good & $31-35$ \\
3. & Fair-aid not needed & $36-40$ \\
4. & Passable - may hang up & $41-45$ \\
5. & Poor - must agitate, vibrate & $46-55$ \\
6. & Very poor & $56-65$ \\
7. & Very, very poor & $>66$ \\
\hline
\end{tabular}

\section{Bulk density:}

Bulk density refers to the measure used to describe a packing of particles or granules. Bulk density is defined as the mass of powder divided by the bulk volume and is expressed in grams per millilitre $(\mathrm{g} / \mathrm{ml})$ although the international unit is kilogram per cubic meter $(1 \mathrm{~g} / \mathrm{ml}=1000$ $\mathrm{kg} / \mathrm{m} 3$ ) because the measurements are made using cylinders. It may also be expressed in grams per cubic centimetre $(\mathrm{g} / \mathrm{cm} 3)$. The equation for determining bulk density $(\rho \mathrm{b})$ is

$$
\mathbf{\rho b}=\mathbf{M} / \mathbf{V b}
$$

where $\rho b=$ Bulk density

$\mathrm{M}=$ Mass of sample in $\mathrm{g}$

$\mathrm{Vb}=$ Total volume of packing

\section{Tapped density:}

Tapped density can be defined as mass of blend in the measuring cylinder divided by its tapped volume .

$$
\rho \mathbf{t}=\mathbf{M} / \mathbf{V t}
$$

Where $\rho t=$ Tapped density

$\mathrm{M}=$ Mass of blend in $\mathrm{g}$

$\mathrm{Vt}=$ Tapped volume of blend in $\mathrm{cm}^{3}$ 


\section{Carr's index:}

The compressibility index (Carr's Index) is a measure of the propensity of a powder to be compressed. It is determined from the bulk and tapped densities and was calculated using the following formulas and is shown in table no. 9:

$$
\text { Carr's Index }=\rho t-\rho b / \rho t * 100
$$

$\rho b=$ bulk density

$\rho t=$ tapped density.

Table 9: Carr's Index

\begin{tabular}{lll}
\hline S.No. & Flow property & Carr's Index (\%) \\
\hline 1. & Excellent & $\leq 10$ \\
2. & Good & $11-15$ \\
3. & Fair & $16-20$ \\
4. & Passable & $21-25$ \\
5. & Poor & $26-31$ \\
6. & Very poor & $32-37$ \\
7. & Very, very poor & $>38$ \\
\hline
\end{tabular}

\section{Hausner's ratio:}

A flow property of powder mixure can be determined by Hausner's ratio. It was calculated by following formula and is shown in table no. 10

Hausner's ratio $=$ Tapped density $/$ Bulk density

A Hausner ratio greater than 1.25 is considered of poor flow ability

Table 10: Hausner's ratio

\begin{tabular}{lll}
\hline S.No. & Flow property & Hausner's ratio \\
\hline 1. & Excellent & $1.00-1.11$ \\
2. & Good & $1.12-1.18$ \\
3. & Fair & $1.19-1.25$ \\
4. & Passable & $1.26-1.34$ \\
5. & Poor & $1.35-1.45$ \\
6. & Very poor & $1.46-1.59$ \\
7. & Very, very poor & $>1.60$ \\
\hline
\end{tabular}

\section{Calibration curve of ciprofloxacin:}

Measurement of spectra of Ciprofloxacin by using UV visible 1600 Shimadzu double beam spectrophotometer and the solvent was $0.1 \mathrm{~N}$ Hydrochloric Acid that was used for measuring the absorbance .

\section{Wavelength Selection}

Absorbance was observed at $278 \mathrm{~nm}$. 


\section{Standard Stock solution}

For standard stock solution $(1000 \mu \mathrm{g} / \mathrm{ml})$, accurately weighed $10 \mathrm{mg}$ of ciprofloxacin was taken and transferred to a volumetric flask and sufficient $0.1 \mathrm{~N}$ Hydrochloric Acid was added to produce $100 \mathrm{ml}$.

\section{Dilutions preparation}

From the standard stock solution of Ciprofloxacin, different dilutions were prepared. Five different dilutions of $2 \mu \mathrm{g} / \mathrm{ml}, 4 \mu \mathrm{g} / \mathrm{ml}, 6 \mu \mathrm{g} / \mathrm{ml}, 8 \mu \mathrm{g} / \mathrm{ml}$ and $10 \mu \mathrm{g} / \mathrm{ml}$. were prepared from 1000 $\mu \mathrm{g} / \mathrm{ml}$ standard stock solution.

\section{Procedure}

After preparation of standard and sample solutions, measurement of the absorbance of different dilutions $(2 \mu \mathrm{g} / \mathrm{ml}, 4 \mu \mathrm{g} / \mathrm{ml}, 6 \mu \mathrm{g} / \mathrm{ml}, 8 \mu \mathrm{g} / \mathrm{ml}$ and $10 \mu \mathrm{g} / \mathrm{ml}$.) in $1 \mathrm{~cm}$ cuvette by using UV-VIS spectrophotometer at the wavelength of maximum absorbance $278 \mathrm{~nm}$, using the blank solution was performed.

\section{Melting point:}

It was determined by using melting point apparatus.

\section{PREPARATION OF LIQUISOLID TABLETS}

A computed amount of medication ought to be dispersed in the non volatile solvent framework (Polysorbate 80, Poly Ethylene Glycol-200) named as fluid vehicle with various medication: vehicle proportion. At that point coming about hot drug ought to be joined into carrier and coating material under nonstop blending in a mortar. Blending process is to be completed in three stages :

\section{Step1:}

System is mixed at a fitting blending rate of one turn for each second for roughly one moment with a specific end goal to equally disperse fluid medication in the powder.

\section{Step 2:}

The fluid/powder admixture is equitably spread as a uniform layer on the surface of a mortar and left remaining for around 5 minute to permit dug solution for be caught up in the inside of powder molecule.

\section{Step 3:}

Powder is scratched off the motor surface by mean of aluminum spatula and afterward mixed with disintegrant like Sodium Starch Glycolate and other outstanding added substances are added by their application and blended for a time of 10 to 20 minute in a mortar. 
The last blend ought to be packed utilizing the manual tabletting machine to accomplish tablet hardness. ( Gavali SM et al,.2011)

\section{CHARACTERISATION:}

\section{Differential scanning calorimetry (DSC):}

Is a thermoanalytical procedure in which the distinction in the measure of heat required to expand the temperature of a sample and reference is estimated as a component of temperature. Both the sample and reference are kept up at almost a similar temperature all through the trial. It is utilized to know the possible interactions amongst drug and excipients utilized as a part of the plan. On the off chance that the characteristic peak for the medication is not present in the DSC thermogram, there means that the medication is as arrangement in liquisolid definition and subsequently it is molecularly scattered inside the framework. Thermal properties of the untreated medication and arranged samples are broke down by DSC. Around $5 \mathrm{mg}$ of test is warmed in a hermetically fixed aluminum pans. Heat keeps running for each sample were set from $30^{\circ} \mathrm{C}$ to $350^{\circ} \mathrm{C}$ at a heating rate of $10^{\circ} \mathrm{C} / \mathrm{min}$, utilizing nitrogen environment of stream rate 100ml/minute. ( Gavali SM et al,.2011)

\section{Fourier transform infra-red spectroscopy (FTIR):}

It is a procedure which is utilized to acquire an infrared range of absorption, emission and Raman scattering of a strong, fluid or gas. FTIR spectrometer at the same time gathers otherworldly information in a wide spectral range. FTIR range of the medication and the readied tests were subjected to IR spectrophotometer under indistinguishable conditions by Potassium Bromide pellet strategy. Range is gathered over a district of 4000-400 cm-1. ( Gavali SM et al,.2011)

\section{$\mathrm{X}$ ray diffraction $(\mathrm{XRD})$ :}

An essential utilization of the procedure is the identification and characterization of mixes in view of their diffraction design. For the portrayal of crystalline state, (XRD) designs are resolved for physical blend of medication and excipients utilized as a part of formulation and for the arranged liquisolid compacts. (Pardhi DM et al,.2010)

\section{Post Compression Evaluations}

\section{Hardness:}

Monsanto hardness tester can be utilized for the assurance of the hardness. The tablet to be tried was held between a settled and moving jaw and perusing of the pointer changed in accordance with zero. The force connected to the edge of the tablet is continuously expanded by propelling 
the screw handle until the point when the tablet breaks. Perusing is noted down and is communicated in $\mathrm{kg} / \mathrm{cm}$

\section{Thickness:}

The crown to crown thickness of tablets is estimated by Vernier Caliper. It is communicated in $\mathrm{mm}$. the thickness variety permitted are $\pm 5 \%$ of the span of the tablet. (Syed IA et al,.2012)

\section{Weight variation:}

20 tablets are chosen arbitrarily from the part and measured independently to check for weight variation. Pharmacopoeial limits are appeared in table no 6.

Table 6: Pharmacopoeial Limits of Weight Variation(Syed IA et al,.2012)

\begin{tabular}{llll}
\hline S.No. & Limit & IP/BP & USP \\
\hline 1. & $10 \%$ & $80 \mathrm{mg}$ or less & $130 \mathrm{mg}$ or less \\
2. & $7.5 \%$ & More than $80 \mathrm{mg}$ or Less than & $130 \mathrm{mg}$ to $324 \mathrm{mg}$ \\
& & $250 \mathrm{mg}$ & \\
3. & $5 \%$ & $250 \mathrm{mg}$ or more & More than $324 \mathrm{mg}$ \\
\hline
\end{tabular}

\section{Uniformity of Drug content:}

The medication substance can be dictated by triturating adequate measure of tablets and powder comparable to normal weight was included $100 \mathrm{ml}$ of suitable buffer solution. Taken after by mixing for $30 \mathrm{~min}$. Dilute reasonably and the absorbance of resultant arrangement was estimated spectrophotometrically. (Syed IA et al,.2012)

\section{In-vitro drug release studies:}

The discharge rate of medication from tablets can be resolved utilizing USP disintegration testing device 2 (paddle technique). The disintegration test performed utilizing $900 \mathrm{ml}$ of reasonable buffer solution at $37 \pm 0.5^{\circ} \mathrm{C}$. (Syed IA et al,.2012)

Table 7 Review of the Drug Molecules with Sustained Release Liquisolid Compact

\begin{tabular}{|c|c|c|}
\hline S.No. & Drug & $\begin{array}{l}\text { Polymer Used In Sustained Release } \\
\text { Formulation }\end{array}$ \\
\hline 1. & Tramadol Hydrochloride & Hydroxy Propyl Methyl Cellulose K4M \\
\hline 2. & Propranolol Hydrochloride & $\begin{array}{l}\text { Hydroxy Propyl Methyl Cellulose ( } 4000 \\
\mathrm{mPa} \cdot \mathrm{s} \text { ) }\end{array}$ \\
\hline 3. & Metoprolo Succinate & Hydroxy Propyl Methyl Cellulose K15M \\
\hline 4. & Theophylline & $\begin{array}{l}\text { Hydroxy Propyl Methyl Cellulose ( } 4000 \\
\mathrm{mPa} \cdot \mathrm{s} \text { ) }\end{array}$ \\
\hline
\end{tabular}

\section{Friability:} $\mathrm{mPa} \cdot \mathrm{s}$ )

The friability of the tablet can decided utilizing Roche Friabilator. It is communicated rate (\%). 10 tablets were at first measured (Winitial) and moved into the friabilator. The friabilator was 
worked at $25 \mathrm{rpm}$ for 4 minutes. The tablets were weighed once more (Wfinal). Furthermore, the $\%$ friability was computed as.

$\mathrm{F}=(\mathrm{W}$ initial $)-(\mathrm{Wfinal}) /($ Winitial $) \times 100($ Syed IA et al,.2012 $)$

\section{CONCLUSION}

Liquisolid systems essentially refer to formulations formed by conversion of the drug in liquid state into dry, non-adherent, free flowing and compressible powder by sorbing the liquid dispersion system to the carrier and coating material. Liquisolid systems show significantly improved bioavailability of drugs due to increased solubility and dissolution rate of poorly water-soluble substances. The liquisolid technique can be also used to design dosage forms with modified release by using hydrophobic carriers instead of hydrophilic carriers. However, the technology of liquisolid systems is in the early stages of its development. It is envisaged that liquisolid systems could play an important role in modern solid dosage forms owing to their advantages (e.g., low production costs, final processing similar to conventional tablets or hard capsules, and unproblematic industrial production).

In conclusion, to enhance the solubility and dissolution of poorly water soluble drugs is still a matter of concern for pharmaceutical scientists. Research of extensive literatures indicates that the development of liquisolid technique is advancing very fast in the past few years. Liquisolid technology is effective for improving dissolution rate as well as bio-availability in practically water insoluble drugs with non-volatile solvents. The technique also sustained the drug release properties of the water soluble drugs by using suitable excipient ratios. Excipients used were commonly used in pharmaceutical industries. All of the excipients are economical and will not affect cost of the final product to a larger extent.

\section{REFERENCES:}

1. LipinskiC. A., Lombardo F., Dominy B. W., Feeney P.J.. Experimental and computational approaches to estimate solubility and permeability in drug discovery and development settings, 46 (2001), page no. 3-26

2. Stegemann S., Leveiller F., Franchi D., de Jong H, Lindén H. When poor solubility becomes an issue: from early stage to proof of concept Eur J Pharm Sci, 31 (2007), page no. 249-261

3. Giliyar C, Fikstad D.T,Tyavanagimatt S., Challenges and opportunities in oral delivery of poorly water-soluble drugs Drug Del Technol, 6 (2006), page no.57-63 
4. Amidon G.L., Lennernas H., Crison J.R., Shah V.P. A theoretical basis for a biopharmaceutic drug classification: the correlation of in vitro drug product dissolution and in vivo bioavailability Pharm Res, pubmed 12 (1999), page no. 413-420

5. Yadav A.V., Shete A.S., Dabke A.P.,Formulation and evaluation of oro-dispersible liquisolid compacts of aceclofenac Indian J Pharm Educ, 44 (2010), page no. 227-235

6. Aguiar A.J., Zelmer A.J., Kinkel A.W.,Deaggregation behaviour of a relatively insoluble substituted benzoic acid and its sodium salt J Pharm Sci, 56 (1979), page no.1243-1252

7. Craig D.Q.M. The mechanisms of drug release from solid dispersions in water-soluble polymers Int J Pharm, 231 (2002), page no.131-144

8. Ebert ,W.R. Soft gelatin capsules: unique dosage form Pharm Tech, 1 (1977), page no. $44-50$

9. Hiremath S.N, Raghavendra R.K., Sunil F. Danki, L.S., Rampure M.V., Swamy P.V., Bhosale U.V. ,Dissolution enhancement of gliclazide by preparation of inclusion complexes with $\beta$-cyclodextrin Asian J Pharm, 2 (2008), page no. 73-76

10. Li D. X., Oh Y. K., Lim S. J., Kim J. O., Yang H. J., Sung J. H., Yong C. S., and Choi H. G.,.Novel gelatin microcapsule with bioavailability enhancement of ibuprofen using spray-drying technique Int J Pharm, 355 (2008), page no. 277-284

11. Kocbek P., Baumgartner S., Kristl J. ,Preparation and evaluation of nanosuspensions for enhancing the dissolution of poorly soluble drugs Int J Pharm, 312 (2006), page no.. 179-186

12. Mahmoud E.B., Nazrul H., Gihan F., Shakeel F., Solubility and dissolution enhancement of tadalafil using self-nanoemulsifying drug delivery system $\mathrm{J}$ Oleo Sci, 63 (2014), page no. 567-576

13. R.H. Müller, Runge S., Ravelli V., Mehnert W, Thünemann A.F., Souto E.B., Oral bioavailability of cyclosporine: solid lipid nano particles $\left(\mathrm{SLN}^{\circledR}\right)$ versus drug nano crystals Int J Pharm, 317 (2006), page no.82-89

14. Javadzadeh Y., Shariati H., Movahhed E. -Danesh, et al. Effect of some commercial grades of microcrystalline cellulose on flowability, compressibility, and dissolution profile of piroxicam liquisolid compacts Drug Dev Ind Pharm, 35 (2009), page no. 243251 
15. Elkordy A.A., Tan X.N., Essa E.A. ,Spironolactone release from liquisolid formulations prepared with Capryol $^{\mathrm{TM}}$ 90, Solutol ${ }^{\circledR}$ HS-15 and Kollicoat ${ }^{\circledR}$ SR 30 D as non-volatile liquid vehicles Eur J Pharm Biopharm, 83 (2013), page no. 203-223

16. Suliman A.S., Anderson R.J., Elkordy A.A., Norfloxacin as a model hydrophobic drug with unique release from liquisolid formulations prepared with PEG 200 and Synperonic PE/L-61 non-volatile liquid vehicles Powder Technol, 257 (2014), page no. 156-167

17. Spireas S., Bolton S.M., Liquisolid systems and methods of preparing same US596855 (1999)

18. Spireas S., Liquisolid system and method of preparing same U.S Patent; 6423339B1 (2002)

19. Spireas S.S., Jarowski C.I., Rohera B.D., Powdered solution technology: principles and mechanism Pharm Res, 9 (1992), page no.1351-1358

20. Spireas S., Sadu S., Enhancement of prednisolone dissolution properties using liquisolid compacts Int J Pharm, 166 (1998), page no.177-188

21. Fahmy R.H., Kassem M.A., Enhancement of famotidine dissolution rate through liquisolid tablets formulation: in vitro and in vivo evaluation Eur $\mathbf{J}$ Pha Biopharm, 69 (2008), page no.993-1003

22. Komala D.R., Janga K.Y., Jukanti R.,BandariS.,Vijayagopal M., Competence of raloxifene hydrochloride loaded liquisolid compacts for improved dissolution and intestinal permeation J Drug Deliv Sci Technol, 30 (2015), page no.232-241

23. K. Sanka, S. Poienti, A.B. Mohd, Divan P.V.Improved oral delivery of clonazepam through liquisolid powder compact formulations: in-vitro and ex-vivo characterization Powder Technol, 256 (2014), page no. 336-344

24. Javadzadeh Y., Musaalrezaei L., Nokhodchi A., Liquisolid technique as a new approach to sustain propranolol hydrochloride release from tablet matrices Int $\mathbf{J}$ Pharm, 362 (2008), page no. 102-108

25. Nokhodchi A., Aliakbar R., Desai S. ,Javadzadeh Y., Liquisolid compacts: the effect of cosolvent and HPMC on theophylline release Colloids Surf B Biointerfaces, 79 (2010), page no.262-269

26. Pavani E., Noman S., Syed I.A., Liquisolid technique based sustained release tablet of trimetazidine dihydrochloride Drug Invention Today, 5 (2013), page no.302-310 
27. El-Hammadi M., Awad N., Investigating the use of liquisolid compacts technique to minimize the influence of $\mathrm{pH}$ variations on loratadine release AA Pharm Sci Tech, 13 (2012), page no.53-58

28. Badawy M.A., Kamel A.O., Sammour O.A., Use of bio-relevant media for assessment of a poorly soluble weakly basic drug in the form of liquisolid compacts: in vitro and in vivo study Drug Delivery, 23 (2016), page no. 818-827

29. Khames A., Liquisolid technique: a promising alternative to conventional coating for improve ment of drug photostability in solid dosage forms Drug Deliv, 10 (2013), page no.1335-1343

30. Javadzadeh Y., Siahi M.R., Asnaashari S., Nokhodchi A., An investigation of physicochemical properties of piroxicam liquisolid compacts Pharm Dev Technol, 12 (2007), page no. 337-343

31. Javadzadeh Y., Siahi M.R., Asnaashari S., Nokhodchi A., Liquisolid technique as a tool for enhancement of poorly water-soluble drugs and evaluation of their physicochemical properties Acta Pharm, 57 (2007), page no.99-109

32. Chella N., Narra N., Rama R.T., Preparation and characterization of liquisolid compacts for improved dissolution of telmisartan ,J Drug Deliv, 2014 , page no.1-10

33. Rajesh K, Rajalakshmi R, Umamaheswari J, Ashok Kumar CK, Liquisolid Technique: A Novel Approach to Enhance Solubility and Bioavailability, International Journal of Biopharmaceutics, 2(1) ( 2011), page no.8-13.

34. Patil U, Mudavath H, Patil S, Jadatkar K, Kumar G, Patel S, Liquisolid Compact: A Review, International Journal of Pharmaceutical Research and Development, 4(3) (2012),page no.151-157.

35. Sambasiva Rao A, Naga A.T, Liquisolid Technology: An Overview, International Journal of Research in Pharmaceutical and Biomedical Sciences, 2(2), (2011) page no.409.

36. Chandel P., Kumari R., Kapoor A., Liquisolid Technique: An Approach For Enhancement Of Solubility, Journal of Drug Delivery \& Therapeutics; 3(4),(2013), page no.131-137.

37. Tayel S.A., Soliman I.I., Louis D., Improvement of dissolution properties of carbamazepine through application of the liquisolid tablet technique Eur $\mathrm{J}$ Pharm Biopharm, 69 (2008), page no.342-347 
38. Lakshmi M.S., Kumara P.S., Kumar T.R., A Novel Approach for Improvement of Solubility and Bioavailability of Poorly Soluble Drugs: Liquisolid Compact Technique, International Journal of Research in Pharmaceutical and Biomedical Sciences, 3(4), (2012) page no.1621-1632.

AJPHR is

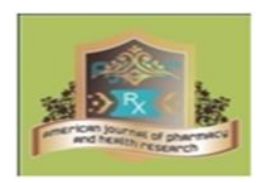

Peer-reviewed monthly

Rapid publication

Submit your next manuscript at editor@ajphr.com / editor.ajphr@gmail.com 